\title{
RANCANG BANGUN MODEL PEMBELAJARAN FLIPPED CLASSROOM SEBAGAI SOLUSI PENINGKATAN DAYA BELAJAR MANDIRI MAHASISWA
}

\author{
Hanifudin Sukri ${ }^{1}$, Doni Abdul Fatah ${ }^{2}$ \\ ${ }^{1}$ Program Studi Teknik Elektro \\ ${ }^{2}$ Program Studi Sistem Informasi \\ Fakultas Teknik, Universitas Trunojoyo Madura \\ Madura, Indonesia \\ ${ }^{1}$ hanifudinsukri@trunojoyo.ac.id, ${ }^{2}$ doni.fatah@trunojoyo.ac.id
}

\begin{abstract}
Abstrak
Pesatnya perkembangan teknologi informasi memudahkan proses belajar mengajar antara dosen dan mahasiswa. Metode belajar mahasiswa pun ikut bergeser dari penggunaan media belajar text book pada media mobile yang merupakan "dunia" generasi milenial yang menawarkan lebih banyak model referensi seperti video, simulasi, dan sebagainya. Model pembelajaran konvensional yang bertumpu pada dosen atau Teacher Centered Learning (TCL) digantikan dengan Student Centered Learning (SCL). Penerapan strategi dan metode pembelajaran yang tepat sesuai dengan perkembangan zaman dan teknologi akan meningkatkan efektivitas pembelajaran mahasiswa dan dapat meningkatkan daya belajar mandiri mahasiswa, dengan metode Flipped Classroom model pembelajaran tradisional dibalik, yang biasanya materi diberikan di kelas dan mahasiswa mengerjakan tugas di rumah. Konsep Flipped Classroom mencakup active learning, keterlibatan mahasiswa, dan podcasting, materi terlebih dahulu diberikan melalui video pembelajaran yang harus ditonton mahasiswa di rumah. Sebaliknya, sesi belajar di kelas digunakan untuk diskusi kelompok, diskusi dengan dosen tentang materi yang sulit untuk dipahami pada saat belajar mandiri dan mengerjakan tugas. Setelah dilakukan evaluasi hasil pembelajaran Flipped Classroom, didapatkan hasil sebanyak $69,2 \%$ media sosial menjadi bagian penting dalam pembelajaran, 76,9\% mahasiswa lebih menyukai pembelajaran dalam bentuk video dibanding dengan model tradisional, 84,6\% mengiyakan model pembelajaran ini dapat meningkatkan keinginan belajar mandiri mahasiswa, $89,2 \%$ belajar dengan menggunakan metode ini memberi manfaat untuk pendidikan masa depan, 69,2\% model pembelajaran ini memberikan banyak waktu mahasiswa untuk melakukan kegiatan di laboratorium, 57,1\% mahasiswa dengan menggunakan metode ini memberikan kesempatan lebih besar komunikasi atau interaksi dengan mahasiswa yang lainnya dan sebesar 64,3\% mahasiswa ternyata lebih termotivasi belajar menggunakan metode Flipped Classroom.
\end{abstract}

Kata Kunci: Teacher Centered Learning, Student Centered Learning, Pembelajaran Tradisional, Flipped Classroom.

\begin{abstract}
The rapid development of information technology facilitates the teaching and learning process between lecturers and students. Student learning methods have also shifted from the use of textbook learning media to gadget media which is a "world" millennial generation that offers more reference models such as videos, simulations and so on. The conventional learning model that relies on lecturers or Teacher Center Learning (TCL) is replaced by Student-Centered Learning (SCL). The application of appropriate learning strategies and methods in accordance with the changing times and technology will increase the effectiveness of student learning and can increase students independent learning power, with the Flipped Classroom method of traditional learning models reversed, which is usually given in class material and students doing assignments at home. The concept of Flipped Classroom includes active learning, student involvement, and podcasting, the material is given in advance through a learning video that students must watch at home. Instead, class sessions are used for group discussions, discussions with lecturers about material that is difficult to understand when studying independently and doing assignments. After evaluating the learning outcomes of Flipped Classroom, 69.2\% of social media became an important part of learning, 76.9\% of students preferred video learning compared to traditional models, $84.6 \%$ agreed that this learning model could increase learning desire student independent, 89.2\% learning using this method provides benefits for future education, $69.2 \%$ this learning model gives students more time to do activities in the laboratory, $57.1 \%$ students using this method provide greater opportunities for communication or interactions with other students and $64.3 \%$ of students were more motivated to learn using the Flipped Classroom method.
\end{abstract}

Keywords: Teacher Centered Learning, Student Centered Learning, Traditional Learning, Flipped Classroom. 


\section{PENDAHULUAN}

Pendidikan merupakan salah satu penentu dari kemajuan sebuah bangsa dan negara, karena dari pendidikan yang baik akan menghasilkan sumber daya manusia yang baik pula, yang mampu bersaing dengan negara-negara lainnya. Pendidikan merupakan usaha agar manusia dapat mengembangkan potensi dirinya melalui proses pembelajaran dan atau cara lain yang dikenal dan diakui oleh masyarakat, sesuai penjelasan UU No. 20/2003 tentang sistem pendidikan nasional. Jadi untuk menghasilkan sistem pendidikan yang baik dan menghasilkan sumber daya manusia yang unggul, diperlukan sebuah metode pembelajaran yang sesuai dengan perkembangan zaman dan teknologi, bukan lagi model pembelajaran konvensional atau tradisional. Model pembelajaran konvensional atau tradisional merupakan pengajaran yang diberikan pengajar kepada sejumlah peserta didik secara bersama-sama dengan metode ceramah, kecenderungan model belajar hapalan yang menekankan informasi konsep, latihan soal teks, serta penilaian masih dengan paper dan pencil test yang hanya menuntut pada satu jawaban yang benar, media pengajar hanya menggunakan kertas, papan dan alat tulis.

Kegiatan pembelajaran yang interaktif dan menyenangkan hampir tidak dapat dirasakan oleh peserta didik pada model pembelajaran tersebut, peran pengajar yang seharusnya menjadi fasilitator dalam pembelajaran tidak kelihatan perannya, peran pengajar sebagai penyampai informasi (transfer of knowledge) masih begitu besar(Rindaningsih, 2018), (Rusdi, Dian Evriyani, 2018) kegiatan pembelajaran seperti ini juga memicu tingkat stres yang tinggi peserta didik pada kelas-kelas yang diikutinya, disamping itu materi atau kegiatan yang disampaikan oleh pengajar ke peserta didik akan susah untuk dipahami.

Penerapan strategi dan metode pembelajaran yang tepat sesuai dengan perkembangan zaman dan teknologi akan meningkatkan efektivitas pembelajaran. Peserta didik akan lebih aktif, waktu pembelajaran di kelas lebih efektif dan kreatif, pengajar dapat melihat perkembangan peserta didiknya dalam sikap, perilaku, dan peningkatan belajar, dan penggunaan media belajar secara optimal. Model Pembelajaran berbasis Flipped Classroom merupakan metode pembelajaran yang tepat dan sesuai dengan perkembangan zaman dan teknologi, dimana pada model pembelajaran ini, pembelajaran yang berpusat pada peserta didik untuk meningkatkan efektivitas pembelajaran. Model pembelajaran ini memanfaatkan teknologi yang mendukung materi pembelajaran yang dapat diakses kapanpun dan dimanapun. Sedangkan waktu pembelajaran di kelas digunakan siswa untuk berkolaborasi dengan rekanrekan proyek, keterampilan praktik, dan menerima umpan balik tentang kemajuan mereka.

Model Flipped Classroom membalik atau menukar apa yang umumnya dilakukan di kelas dan apa yang umumnya dilakukan sebagai pekerjaan rumah kemudian (Maolidah, Ruhimat, \& Dewi, 2017). Peserta didik membaca materi, mendengarkan video pembelajaran sebelum mereka datang ke kelas dan mereka mulai berdiskusi, bertukar pengetahuan, menyelesaikan masalah, dengan bantuan peserta didik lain maupun pengajar. Selain itu model Flipped Classroom melatih peserta didik untuk 
mengembangkan ide dan kreativitas mereka, mampu berpikir secara kritis, inovatif dan tidak mudah terpengaruh oleh pendapat orang lain dan membantu mereka dengan tugas, praktikum dan proyekproyek yang menantang dengan memberikan kontrol belajar yang lebih besar serta berani bertangung jawab atas tindakannya sendiri. Penggunaan model pembelajaran Flipped Classroom dalam proses pembelajaran diharapkan mampu membantu siswa yang mengalami kesulitan belajar, sehingga peserta didik yang mengalami kesulitan belajar atau tertinggal dapat mengikuti pembelajaran dengan baik.

Penelitian oleh (Gunyou, 2015), menjelaskan desain pembelajaran Flipped Classroom dengan siklus pada Gambar 1 .

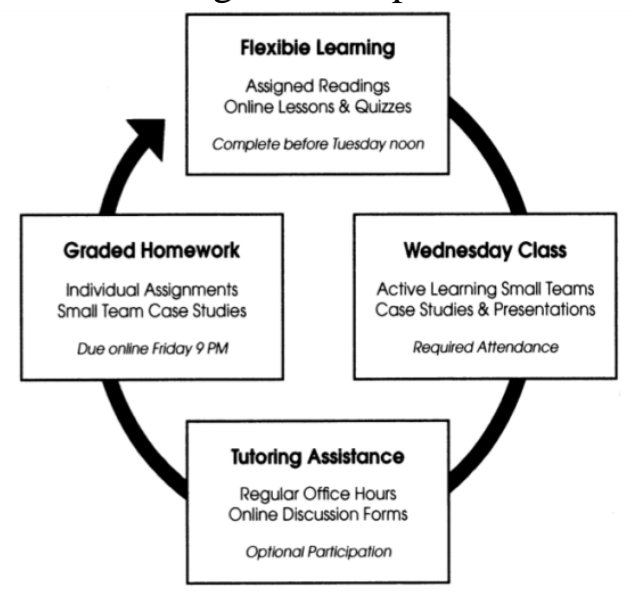

Gambar 1. Siklus desain pembelajaran Flipped Classroom (Gunyou, 2015)

Materi diberikan dalam bentuk video sehingga peserta didik dapat mengulangi materi-materinya sesuai dengan kebutuhan, selain itu ada juga kuis secara online dalam bentuk video serta diberikan studi kasus untuk memecahkan masalah dalam bentuk diskusi kelompok serta peran pengajar sebagai fasilitator dalam proses belajar (Gunyou, 2015).

(Fulton, 2014) menjelaskan bahwa ada 10 sebab mengapa menggunakan metode Flipped Classroom : peserta didik lebih memahami materi sesuai dengan cara mereka masing-masing; mengerjakan latihan atau proyek di kelas akan membuat pengajar lebih mengetahui gaya belajar dan kemampuan pemahaman peserta didik baik kesulitan yang dialaminya; pengajar dapat memperbarui kurikulum sesuai kebutuhan serta menyediakannya waktu selama 24 jam; peserta didik dapat mengakses materi pembelajaran dimanapun berada dan dalam waktu kapanpun; antar sesama pengajar dapat mengembangan dan melihat video materi pembelajarannya secara profesional; efisiensi pembelajaran di kelas; soal latihan dapat dipantau oleh orang tua; kompetensi peserta didik meningkat, menarik dan menjanjikan untuk pendalaman materi ke level yang lebih tinggi; menciptakan teori pendukung pada pendekatan-pendekatan yang baru; dan memanfaatkan teknologi sesuai dengan kemajuan zaman sekarang.

(Song \& Kapur, 2017) menjelaskan dalam penelitiannya, seperti pada Gambar 2.
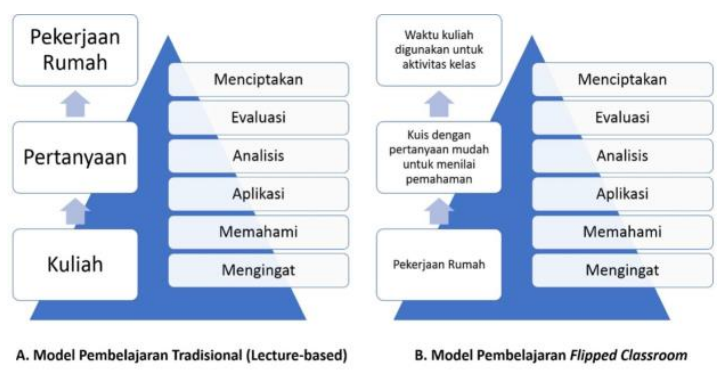

Gambar 2. Proses kelas tradisional (A) dibandingkan dengan Flipped Classroom (B) selaras dengan taksonomi Bloom yang direvisi(Song \& Kapur, 2017)

Gambar 2 mengungkapkan bahwa perbandingan pembelajaran konvensional dengan pembelajaran menggunakan model Flipped Classroom bagi peserta didik menengah. Proses pembelajarannya 
menunjukkan perbedaan dimana peserta didik yang diajar menggunakan pembelajaran konvensional masih kesulitan dalam memahami materi dan mengalami kesalahan yang sama saat pretes dan pos-tes. Sedangkan peserta didik yang menggunakan pembelajaran model Flipped Classroom mengalami peningkatan pesat dalam memahami dan menyelesaikan masalah yang didapatkan, terlihat dari hasil pre-tes dan pos-tes peserta didik yang sudah mampu menjawab dengan tepat.

Kemajuan teknologi menciptakan tekanan besar pada generasi muda untuk mengikuti perkembangan baru, pendidik harus mengembangkan metode peningkatan pembelajaran yang inovatif untuk membantu mempersiapkan generasi ini terhadap tantangan di masa depan. Salah satu alasannya adalah rasio mahasiswa dibanding dosen yang semakin besar. Selain itu, kebutuhan mahasiswa akan keterampilan pendidikan berbasis kompetensi. Termasuk keterampilan dalam menumbuhkan kebiasaan belajar mandiri dan seumur hidup. Penelitian juga menunjukkan bahwa Flipped Classroom berhubungan dengan pencapaian akademik yang lebih tinggi bila dibandingkan dengan metode pembelajaran tradisional (lecture based)(Oktaria et al., 2019).

\section{METODE PENELITIAN}

Penelitian ini dilakukan pada program studi teknik elektro dengan mata kuliah Manajemen Basis Data. Alasan mengambil mata kuliah ini dalam penelitian karena metode Flipped Classroom sangat sesuai diterapkan pada mata kuliah dengan model praktikum.
Penerapkan metode Flipped Classroom pada penelitian ini dilakukan dengan beberapa kegiatan yaitu :

Identifikasi masalah dilakukan sebelum proses pembelajaran ini dilakukan. Peserta didik diminta mengisi kuesioner untuk survei terkait tentang bagaimana model pembelajaran yang akan dilakukan pada perkuliahan atau proses pembelajaran dan bagaimana cara mereka ketika menghadapi permasalahan serta kemandirian mereka terkait materi yang diajarkan oleh pengajar baik dalam mendapatkan materi, kesulitan hingga media mereka dalam melakukan pembelajaran.

Menyusun outline materi bahan ajar berupa video, dengan membuat outline materi bahan ajar tersistematis dan jelas serta melakukan tahapan kegiatan ini secara profesional yang mengacu pada RPS mata kuliah Manajemen Basis Data. Sehingga, video yang dihasilkan merupakan video yang sesuai dengan capaian pembelajaran.

Merekam dan menyunting video materi bahan ajar Flipped Classroom. Langkah ini begitu penting karena sebagai dasar pembuatan video yang valid serta sebagai dasar pelaksanaan Flipped Classroom. Pembuatan dan penyuntingan video dilakukan dengan cermat dan hatihati dengan menggunakan sumber data valid dan terpercaya.

Validasi Video Materi dan koordinasi dengan para pengajar mata kuliah, dengan mengecek lagi kesesuaian pada RPS mata kuliah Manajemen Basis Data Prodi Teknik Elektro dan kemudian mempresentasikan di depan tim pengajar mata kuliah Manajemen Basis Data dengan tujuan agar video yang telah dibuat harus sistematis, jelas, efektif dan efisien serta sesuai dengan kebutuhan mahasiswa. 
Apabila pada proses ini terdapat bagian yang tidak sesuai dengan materi maka akan disunting ulang.

Penerapan model pembelajaran Flipped Classroom. Pada penerapan model pembelajaran terjadi dalam 3 fase yaitu fase pra kelas, fase dalam kelas dan fase aplikasi.

Evaluasi Hasil Pembelajaran Flipped Classroom, dengan melakukan beberapa kegiatan yaitu menyebarkan angket melalui daring, dan analisis hasil evaluasi Flipped Classroom. Tahapan ini dilakukan setelah pelaksanaan pembelajaran Flipped Classroom terjadi, untuk mengetahui seberapa manfaat dan dampak pelaksanaan metode ini pada proses belajar mahasiswa.

\section{HASIL PENELITIAN DAN PEMBAHASAN}

Penerapan media ini dilakukan dengan memanfaatkan aplikasi google classroom yang sudah disediakan oleh kampus. Peserta didik masuk dengan surel trunojoyo.ac.id atau gmail.com kemudian memilih kelas yang akan dituju dengan memasukan kode kelas atau mengikuti tautan sesuai dengan kelasnya. Setelah joint kelas, peserta didik dapat mengikuti semua kegiatan yang dilakukan di dalam kelas tersebut baik informasi perkuliahan, materi, ulangan hingga diskusi.

Sebelum proses pembelajaran ini dilakukan, peserta didik diminta mengisi kuisioner untuk survei terkait tentang bagaimana model pembelajaran yang akan dilakukan pada perkuliahan atau proses pembelajaran. Selain itu, bagaimana cara mereka ketika menghadapi permasalahan dan kemandirian mereka terkait materi yang diajarkan oleh pengajar baik dalam mendapatkan materi, kesulitan hingga media mereka dalam melakukan pembelajaran. Untuk lebih jelasnya berikut

hasil kuisioner yang telah dilakukan, dengan keterangan pada kuisioner adalah : $\mathrm{SL}=$ Selalu, $\mathrm{P}=$ Pernah, $\mathrm{SR}=$ Sering, $\mathrm{TP}$ $=$ Tidak Pernah, KD = Kadang-kadang. Dengan beberapa pertanyaan sebagai berikut :

- Saya belajar terlebih dahulu sebelum diajarkan oleh dosen,

- Saya belajar menggunakan text book.

- Saya belajar menggunakan gawai/handphone,

- Saya belajar melalui media audio visual (video).

- Sesudah pertemuan saya mencoba mengulangi materi kembali di rumah,

- Ketika dosen memberi kesempatan untuk bertanya, maka kesempatan itu saya biarkan saja meskipun ada materi pelajaran yang belum saya pahami

- Setiap ada permasalahan dalam memahami materi, saya bertanya kepada orang lain atau dosen.

- Jika materi pelajaran belum saya pahami saya berusaha mencari referensi lain untuk membantu memahami.

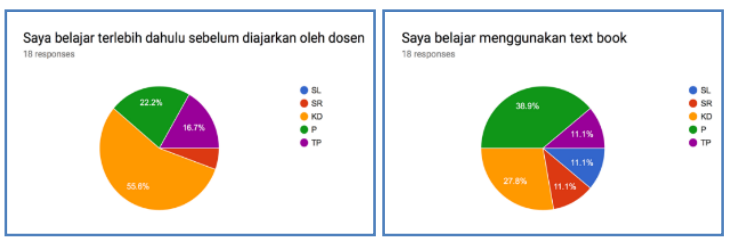

Gambar 3. Salah satu contoh hasil survei identifikasi masalah model pembelajaran

Beberapa pertanyaan tersebut
disebarkan secara daring kepada
mahasiswa kelas Manajemen Basis Data.
Hasil yang diperoleh bahwa metode
belajar peserta didik ikut bergeser dari
penggunaan media belajar text book pada
media gawai yang merupakan "dunia"
generasi milenial yang menawarkan lebih
banyak model referensi seperti video,
simulasi, dan sebagainya. (Oliver, 2013)


Model pembelajaran konvensional yang bertumpu pada dosen atau yang biasa disebut Teacher Centered Learning (TCL) digantikan dengan model pembelajaran Student Centered Learning (SCL).

Menyusun outline materi bahan ajar berupa video, hal pertama yang dilakukan dalam proses penyusunan ialah membuat outline materi bahan ajar tersistematis dan jelas serta melakukan tahapan kegiatan ini dengan profesional dengan mengacu pada RPS mata kuliah Manajemen Basis Data. Sehingga, video yang dihasilkan merupakan video yang sesuai dengan capaian pembelajaran.

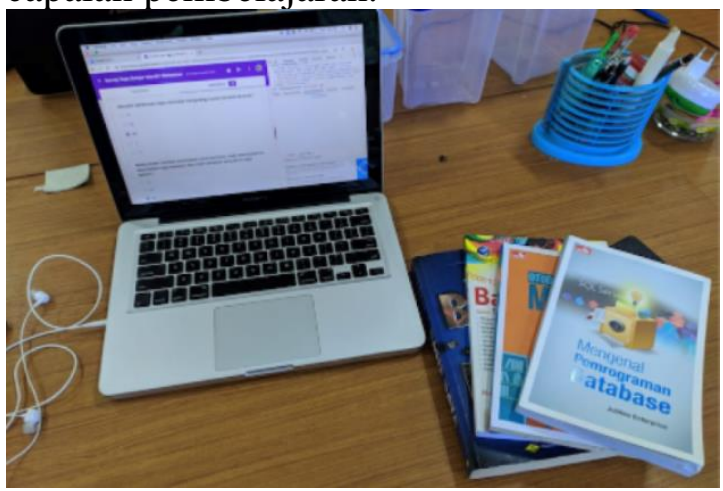

Gambar 4. Pembuatan outline materi bahan ajar

Merekam dan menyunting video materi bahan ajar Flipped Classroom. Setelah menyusun outline materi bahan ajar, langkah selanjutnya mulai merekam dan menyunting materi bahan ajar berupa video. Langkah ini begitu penting sebagai dasar pembuatan video yang valid serta sebagai dasar pelaksanaan Flipped Classroom.

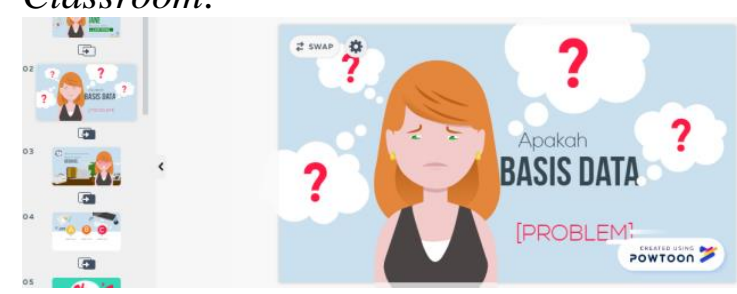

Gambar 5. Pembuatan dan penyuntingan video

Pembuatan dan penyuntingan video dilakukan dengan cermat dan hati-hati dengan menggunakan sumber data valid dan terpercaya serta mengedepankan bahasa Indonesia dan mengabungkan dengan animasi untuk dapat menarik perhatian dan mudah dipahami dengan video yang dihasilkan memiliki kualitas yang baik.

Validasi Video Materi dan koordinasi dengan para pengajar matakuliah. Setelah merekam dan menyunting video materi kemudian melakukan validasi video dengan mengecek lagi kesesuaian pada RPS mata kuliah Manajemen Basis Data prodi teknik elektro dan kemudian mempresentasikan di depan tim pengajar Mata kuliah Manajemen Basis Data. Video yang telah dibuat harus sistematis, jelas, efektif dan efisien serta diperhatikan lagi dengan seksama, sehingga apabila terdapat bagian yang tidak sesuai dengan materi maka akan disunting ulang. Video atau bahan yang valid dan terpercaya sangat penting agar dapat memberikan informasi yang benar dan tidak menyesatkan.

Dari proses penyusunan materi bahan ajar sebagai sarana Flipped Classroom dibuatkan video pembelajaran yang bertujuan ketika peserta didik sebelum masuk kelas dan ketika masih kurang paham dengan materi yang disampaikan akan mengulanginya, sehingga lebih dalam lagi dalam memahami materi perkuliahan. Berikut kurang lebih materi dalam bentuk video dan powerpoint yang mengacu pada RPS mata kuliah Manajemen Basis Data :

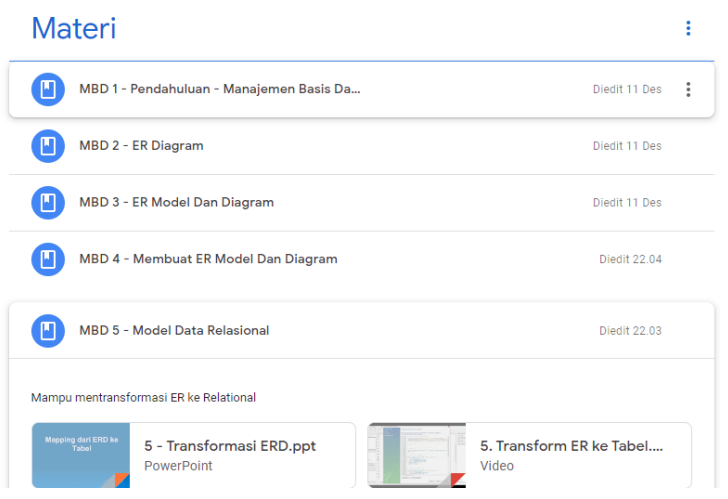

Gambar 6. Materi Mata kuliah Manajemen Basis Data dalam bentuk audio visual 
Pada model pembelajaran Flipped Classroom yang terjadi sebelum proses pembelajaran dilakukan di kelas (pra kelas), peserta didik diberi pengarahan terkait dengan tujuan kegiatan pembelajaran yang harus dilakukan. Langkah selanjutnya adalah meminta peserta didik untuk aktif mempelajari dan memahami lebih dalam lagi materi yang telah disiapkan oleh pengajar dalam hal ini yaitu bentuk audio visual dengan cara kegiatan diskusi kelompok, pemecahan masalah, atau pembelajaran berbasis masalah. Langkah terakhir adalah mengukur sejauh mana pemahaman peserta didik terhadap isi materi yang telah dipelajarinya dengan cara memberikan pertanyaan, melibatkan dalam kegiatan proyek, praktikum, survei atau observasi portofolio, studi banding dan memberikan ujian akhir untuk mengukur tingkat pemahamannya serta memberikan umpan balik dan evaluasi terkait pencapaian pembelajaran pada masing-masing peserta didik.

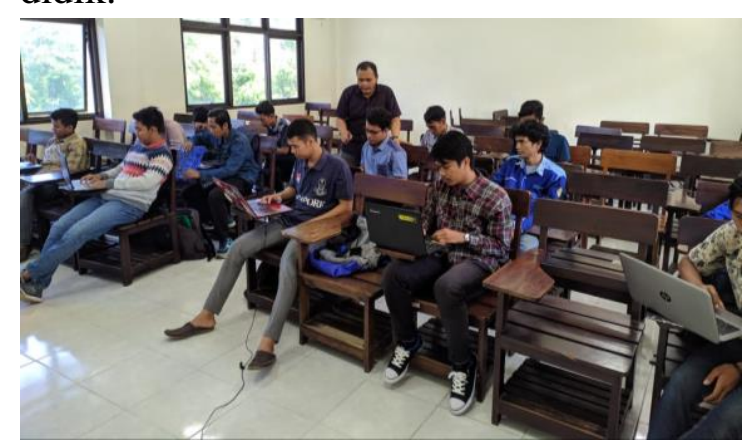

Gambar 7. Proses kegiatan pembelajaran

Setelah menerapkan Flipped Classroom sebagai metode pembelajaran untuk mengetahui seberapa besar manfaat/dampak penerapan metode tersebut dan untuk mengidentifikasi daya belajar mandiri mahasiswa akan digunakan alat ukur berupa kuesioner. Kuesioner disebarkan melalu daring kepada mahasiswa Prodi Teknik Elektro sehingga dapat dibandingkan dengan kuisioner evaluasi yang disebar setelah Flipped Classroom diterapkan, dengan beberapa pernyataan :

- Media sosial (YouTube, Twitter, Facebook) merupakan bagian penting dalam pembelajaran saya

- Saya lebih suka pelajaran yang dipimpin dosen tradisional daripada video pelajaran

- Flipped Classroom meningkatkan keinginan belajar mandiri saya

- Belajar dengan cara menggunakan Flipped Classroom akan bermanfaat bagi saya dalam pendidikan masa depan saya.

- Flipped Classroom lebih menarik daripada instruksi kelas tradisional.

- Flipped Classroom memberi saya lebih banyak waktu untuk melakukan kegiatan di laboratorium

- Saya suka menonton pelajaran di video

- Saya lebih termotivasi untuk belajar dengan metode Flipped Classroom.

- Flipped Classroom memberi saya kesempatan lebih besar untuk berkomunikasi dengan mahasiswa lain

Pernyataan di atas disebarkan dengan media daring kepada mahasiswa kelas manajemen basis data prodi Elektro guna untuk mengetahui dampak dari penerapan model pembelajaran Flipped Classroom :
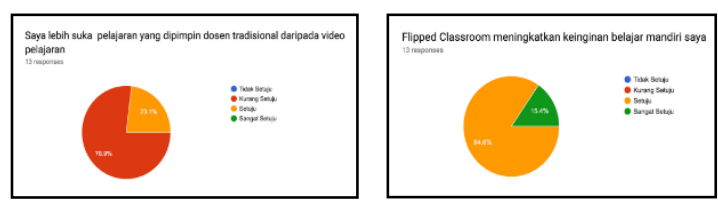

Gambar 8. Contoh hasil survey tentang (a).

Saya lebih suka pelajaran yang dipimpin dosen tradisional daripada video pelajaran (b).

Flipped Classroom meningkatkan keinginan belajar mandiri saya 

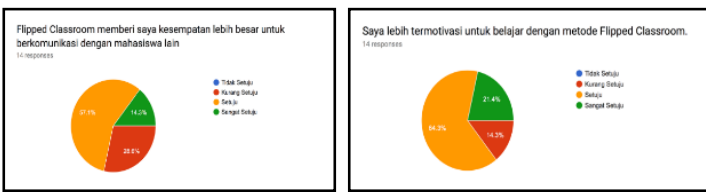

Gambar 9.Contoh hasil survey tentang(a).

Flipped Classroom memberi saya kesempatan lebih besar untuk berkomunikasi dengan mahasiswa lain, (b). Saya lebih termotivasi untuk belajar dengan metode Flipped Classroom

Setelah dilakukan evaluasi hasil pembelajaran Flipped Classroom didapatkan hasil sebanyak $69,2 \%$ media sosial menjadi bagian penting dalam pembelajaran, $76,9 \%$ mahasiswa lebih menyukai pembelajaran dalam bentuk video dibanding dengan model tradisional, $84,6 \%$ mengiyakan model pembelajaran ini dapat meningkatkan keinginan belajar mandiri mahasiswa. Selain itu 89,2\% mahasiswa belajar dengan menggunakan metode ini memberi manfaat untuk pendidikan masa depan, 69,2\% model pembelajaran ini memberikan banyak waktu mahasiswa untuk melakukan kegiatan di laboratorium, 57,1\% mahasiswa dengan menggunakan metode ini memberikan kesempatan lebih besar komunikasi atau interaksi dengan mahasiswa yang lainnya dan sebesar 64,3 $\%$ mahasiswa ternyata lebih termotivasi belajar menggunakan metode Flipped Classroom

\section{KESIMPULAN DAN SARAN}

Berdasarkan kegiatan pembelajaran dengan metode Flipped Classroom yang di implementasi sebagai media pembelajaran pada era industri 4.0, dapat disimpulkan :

1. Berdasarkan respon kegiatan yang dilaksanakan menunjukkan bahwa daya belajar mandiri peserta didik Program Studi Teknik Elektro Universitas Trunojoyo Madura masih perlu ditingkatkan. Selain itu, metode Flipped Classroom yang berpusat pada peserta didik Student Centered Learning (SCL) dapat meningkatkan daya belajar mandiri mahasiswa. Di sisi lain, dengan dilaksanakan program ini juga mengalami peningkatan dari hasil evaluasi pembelajaran mahasiswa. Hal tersebut dapat dilihat dari nilai hasil evaluasi pembelajaran mahasiswa setelah dicoba diterapkannya metode Flipped Classroom.

2. Menciptakan model pembelajaran yang memaksimalkan waktu pembelajaran dan tidak terbatas pada kegiatan tatap muka di kelas saja, melainkan pembelajaran di luar kelas atau ditempat yang para peserta didik nyaman untuk belajar serta terjadinya interaksi antar peserta didik maupun antar peserta didik dengan pengajar secara aktif dalam pemecahan masalah (problem solving).

3. Peserta didik yang ketinggalan atau belum paham tentang pelajaran atau materi yang sudah diajarkan oleh pengajar dapat mengulang kembali atau mempelajarinya lebih dalam lagi secara mandiri dengan kontrol belajar dari pengajar melalui metode Flipped Classroom berupa video pembelajaran.

Untuk meningkatkan daya belajar mandiri mahasiswa maka ada beberapa saran yang dapat direkomendasikan untuk pengembangan metode Flipped Classroom, diantaranya adalah :

1. Kegiatan yang bersifat ilmiah, khususnya yang menyangkut proses belajar mengajar perlu didorong oleh dosen dan civitas akademika dengan tugas-tugas yang mengharuskan mahasiswa untuk terus meningkatkan daya belajarnya.

2. Untuk hasil yang lebih baik lagi maka dalam Penyusunan Materi / Bahan Ajar 
Berupa Video dan Modul dapat disesuaikan dengan capaian pembelajaran yang ada pada kurikulum. Selain itu, metode Flipped Classroom sangat cocok diterapkan pada mata kuliah yang sifatnya praktik untuk membantu pemahaman peserta didik lebih dalam lagi.

3. Perlunya berkolaborasi antar pengajar dengan mata kuliah yang sama dan memaksimalkan teknologi e-learning yang dimiliki kampus. Hal ini akan membuat terjadinya pembelajaran yang kondusif dan menyenangkan. Bagian ini berisi kesimpulan yang diperoleh peneliti sesuai dengan tujuan dilakukannya penelitian tersebut. Sedangkan saran berisi pokok-pokok hasil penelitian yang disarankan kepada peneliti lain dalam menerapkan atau melanjutkan penelitian tersebut.

\section{DAFTAR PUSTAKA}

Fulton, K. P. (2014). 10 reasons to flip, The Phi Delta Kappan. Phi Delta Kappan International, 94(2), 20-24. Retrieved from https://www.jstor.org/stable/41763589

Gunyou, J. (2015). I Flipped My Classroom: One Teacher's Quest to Remain Relevant. Journal of Public Affairs Education, 21(1), 13-24. https://doi.org/10.1080/15236803.2015. 12001813

Maolidah, I. S., Ruhimat, T., \& Dewi, L. (2017). Efektivitas Penerapan Model Pembelajaran Flipped. Edutcehnologia, 3(2), 160-170.

Oktaria, D., Hamidi, S., Kedokteran, F., Lampung, U., Kedokteran, B. P., Kedokteran, F., ... Lampung, U. (2019). Metode Pembelajaran Flipped Classroom dalam Pendidikan Kedokteran. Medula, 8(2), 47-54.

Oliver, J. (2013). FLIP YOUR CLASS NOW;FLIPPED CLASSROOM MELALUI PENERAPAN MODEL
PEMBELAJARAN EXO OLO TASK. Journal of Chemical Information and Modeling, 53(9), 1689-1699. https://doi.org/10.1017/CBO978110741 5324.004

Rindaningsih, I. (2018). Efektifitas Model Flipped Classroom dalam Mata Kuliah Perencanaan Pembelajaran Prodi S1 PGMI UMSIDA. Proceedings of the ICECRS, 1(3), 51-60. https://doi.org/10.21070/picecrs.v1i3.13 80

Rusdi, Dian Evriyani, D. K. P. (2018). PENGARUH MODEL PEMBELAJARAN PEER INSTRUCTION FLIP DAN FLIPPED CLASSROOM TERHADAP HASIL BELAJAR KOGNITIF SISWA PADA MATERI SISTEM EKSKRESI. BIOSFER: JURNAL PENDIDIKAN BIOLOGI (BIOSFERJPB, 11(2), 100105. https://doi.org/0853-2451

Song, Y., \& Kapur, M. (2017). How to flip the classroom - "productive failure or traditional Flipped Classroom" pedagogical design? Educational Technology and Society, 20(1), 292305. 